\title{
Veterinary Pathology - A Path Forward with New Directions and Opportunities
}

\author{
Tracy Stokol* \\ Department of Population Medicine and Diagnostic Sciences, College of Veterinary Medicine, Cornell University, Ithaca, NY, USA
}

Keywords: diagnostic assays, imaging modalities, wildlife disease, emerging disease, nanomedicine, consensus statements, genome-wide association studies

As veterinary pathologists, we have a broad knowledge of disease processes in an array of species with variable physiology and response to disease. The breadth of areas where veterinary pathologists are active has led us to sub-specialize in particular species, organ systems, infectious agents, or sub-disciplines, such as forensic science. We are a group with tremendously diverse interests and expertise that includes basic and clinically applied research, drug discovery and preclinical toxicologic testing, diagnostic testing and quality assurance, public health and governmental policy, public outreach, and education. Our diversity of interests is both a strength and a challenge. Should we strive to maintain a unified discipline or divest into defined subspecialties? How should we define ourselves as pathologists? What core skill sets and competences should we include for certification and how do we prepare our trainees for the future? Should we have one international certification? Finally, how do we make our trainees aware of the many opportunities available to them?

The American College of Veterinary Pathologists is addressing these challenges in part by revising the structure and content of the specialty board examination. A working group has also been established to develop a "strategic plan for the future." This group convened at the 2015 annual meeting and, in its initial discussions, recognized that (1) veterinary pathologists must adapt and respond to the changing needs for our stakeholders and (2) a renewed importance should be placed on research in training programs. ${ }^{1}$ Although the working group is likely several years away from delivering final recommendations, it seems likely that emphasis will be placed on research training. There is currently no stipulation for a research component in residency programs. In my view, building the infrastructure to support investigative research as an integral part of our training programs would be a positive step forward. By expanding our knowledge and informing future diagnostic practice, research will help keep our discipline relevant, vital, and current. I believe that training in investigative research will stimulate critical thinking in our trainees and potentially increase their competitiveness and the qualified applicant pool for faculty and leadership positions. It will also help feed the intellectual curiosity that drives us.

Our field is defined by the juxtaposition of descriptive and mechanistic explorations of disease processes. Identifying abnormalities and characterizing known and emerging diseases is a critical facet of what we do. Salient examples include the pathologist's role in recognizing the emergence of West Nile virus in the United States (1) and elucidating the fungal cause of white nose syndrome in bats (2). This descriptive research is an essential part of diagnostic pathology. Yet, we, as pathologists, also study the step-by-step development of disease from the molecular and genetic level to the animal level. Our profession strives to develop tools to identify disease at its earliest stage, when interventions are more likely to be successful. This effort is crucial to global health, as diseased animals affect their environment causing downstream ecological effects on humans, plants, and other animals. To help us explore disease at all these levels and the complex interrelationships between

${ }^{1}$ http://www.acvp.org/PDF/2016_ACVP_June_Newsletter_WEB.pdf 
animal and human health, I believe we should continue to take advantage of new and emerging disciplines, incorporating them into our investigational pursuits, as outlined below. We can also forge new cross-disciplinary partnerships and become leaders and essential contributors in collaborative teams. We should strive to ask novel questions and challenge dogma in animal disease that will help inform human studies and increase our competitiveness with national funding agencies.

\section{EPIGENETICS AND GENETICS}

The genomes of several animal species have been sequenced and annotated, including dogs (3), cats, ${ }^{2}$ and horses. ${ }^{3}$ These resources have allowed us to employ genome-wide association mapping to identify genetic abnormalities in inbred animals with simple disease traits that have helped inform similar diseases and normal development in humans (4-6). These breakthroughs have in turn resulted in the development of diagnostic tests for the genetic traits, which has potential for reducing disease prevalence (6-8). Genetic screening has also revealed associations with specific loci for complex diseases (9). Further investigation of these loci may lead us to discover causative genes and develop relevant diagnostic tests. Despite the rapid advances in genomic mapping, many challenges remain. For example, we are just beginning to explore epigenetic patterns in animals $(10,11)$ but lack important tools, such as promoter arrays. We also need more information on cancer genomes in animals. I expect that these tools will eventually be developed. Our discipline must be ready to incorporate these advances in genomics into our training and diagnostic programs.

\section{NANOENGINEERING}

The burgeoning field of biomedical engineering has rapidly morphed from basic research into translational medicine, with the application of engineering principles to cancer diagnostics, drug delivery, imaging, and infectious disease detection, to name a few applications (12-15). This field, together with genomic analysis, has ushered in personalized medicine in humans. Application of nanoengineering tools has just begun in veterinary medicine (16-18), but the goal of personalized medicine for pet animals is likely to come sooner rather than later. As pathologists, we hold a unique position where we can be both leaders and an integral member of multidisciplinary teams in the charge toward personalized medicine.

\section{DIAGNOSTIC IMAGING}

The introduction of powerful advanced techniques, such as imaging flow cytometry (19-21) and histology-directed imaging mass spectrophotometry (22), is yielding new insights into disease pathogenesis. As dedicated instruments become more commonplace and cost-effective, it will only be a matter of time

${ }^{2}$ http://www.ncbi.nlm.nih.gov/genome?term =felis\%20catus ${ }^{3}$ http://www.uky.edu/Ag/Horsemap/ before these technologies enter the diagnostic realm. I, for one, am excited by the opportunity that these modalities represent. Pinpoint accuracy for infectious disease diagnosis, novel insights into biochemical pathways that lead to pathology - the possibilities are endless.

\section{CONSENSUS STATEMENTS AND STANDARDIZATION OF TESTING}

Unlike human medicine, our diagnostic activities are not federally regulated. Veterinary diagnostic laboratories do not have to follow Clinical Laboratory Improvement Amendments regulations. ${ }^{4}$ Nevertheless, many laboratories voluntarily participate in external proficiency testing, with recommendations for this testing being established by the American Society of Veterinary Clinical Pathology (23). Guidelines and consensus statements have been generated for several diagnostic activities, including reference interval establishment (24), prognostic markers in cancer (25), flow cytometric reporting in canine hematopoietic neoplasia (26), immunocytochemical staining (27), and viscoelastic-based hemostasis testing (28), to name a few examples. Similarly, cytologic (29) and histologic $(30,31)$ grading schemes have been proposed for various tumors. Importantly, these guidelines are the culmination of efforts of multiple investigators and truly represent a global approach ("One Pathology"). Their frequency of citation and routine application during diagnostic testing attests to the usefulness of these guidelines. I believe that there is a clear need for new guidelines for our vast array of assays, such as histopathologic tumor grading, clonality assays and reporting, and flow cytometric methods. Ideally, these guidelines should be grounded in evidence-based medicine and have a built-in plan for re-evaluation. Up-to-date guidelines are crucial for standardization and allow cross-laboratory comparison of results, increasing the usefulness of results and our confidence in the provided data. There is also a need for increased availability of affordable veterinary-specific proficiency testing. This is particularly pertinent for assays that use species-specific reagents, such as flow cytometry and clonality testing. In the absence of enforced regulation, it falls to us, the pathologists, and our Colleges and Societies, to generate more of these consensus statements or recommendations for standardization of testing and reporting.

\section{HUMAN-WILDLIFE BOUNDARIES}

Human activity continues to encroach upon uninhabited areas perturbing ecosystems and wildlife populations. A consequence of bringing human populations into close contact with previously isolated wild species is the interspecies transmission of infectious disease. Recently, we have seen outbreaks of Ebola and Zika viruses in humans, viruses that have previously been largely restricted to wildlife $(32,33)$. Conversely, viruses that are typically considered pathogens of domestic animals, such as canine distemper, have spread into naive wildlife, with devastating

${ }^{4}$ https://wwwn.cdc.gov/clia/ 
effects (34). Technologic advances, such as hydrofracking, have allowed for the increased utilization of previously inaccessible natural resources. Yet, these come at a health cost to animals and humans (35). Wildlife species are sentinels of environmental changes, the proverbial "canary in the coal mine." The emergence and spread of fungal diseases, such as Pseudogymnoascus destructans (2) and chytridiomycosis (Batrachochytrium dendrobatidis) (36), emphasizes our need to be continually and actively vigilant at screening wildlife for environmental changes that may affect human and animal health. Veterinary pathologists will continue to play a vital and prominent role in identification and investigation of these diseases.

The scope of this section of Frontiers in Veterinary Science is pathology - the study of disease - at a genetic (or epigenetic), molecular, cellular, tissue, organism, and herd level in animals. The scope encompasses the study of factors that contribute to disease, such as the aforementioned environmental changes. Our focus is animal health. Through improving animal health, we improve the health and well-being of humans, whose lives are intricately tied to and reliant on the animals that serve as food, companions, and workers. We accept various manuscript types ${ }^{5}$ and strongly encourage submission of prospective descriptive or hypothesisdriven studies in topics related to pathology. To complement our current research topics, future planned research topics are hematopoietic neoplasia, hemostasis, and wildlife as sentinels of disease.

So why publish in Frontiers in Veterinary Science?

- Open-access: this makes our research available to everyone.

- Rapid publication: with high expectations for productivity for early career pathologists, there is an urgent need for rapid publication. Fast turnaround times are only available through non-traditional publication avenues, such as open-access online journals. The average time from submission to online publication is around 2-3 months for Frontiers.

- Minimal stylistic editing: write your manuscript in active voice and your own style. Tell us your story.

- Copyright: authors retain copyright through a Creative Commons License. If you are a member of Linked-In, Research

${ }^{5} \mathrm{http} / /$ journal.frontiersin.org/journal/veterinary-science\#article-types

\section{REFERENCES}

1. Steele KE, Linn MJ, Schoepp RJ, Komar N, Geisbert TW, Manduca RM, et al. Pathology of fatal West Nile virus infections in native and exotic birds during the 1999 outbreak in New York City, New York. Vet Pathol (2000) 37(3):208-24. doi:10.1354/vp.37-3-208

2. Blehert DS, Hicks AC, Behr M, Meteyer CU, Berlowski-Zier BM, Buckles EL, et al. Bat white-nose syndrome: an emerging fungal pathogen? Science (2009) 323(5911):227. doi:10.1126/science.1163874

3. Lindblad-Toh K, Wade CM, Mikkelsen TS, Karlsson EK, Jaffe DB, Kamal M, et al. Genome sequence, comparative analysis and haplotype structure of the domestic dog. Nature (2005) 438(7069):803-19. doi:10.1038/nature04338

4. Wiik AC, Wade C, Biagi T, Ropstad EO, Bjerkas E, Lindblad-Toh K, et al. A deletion in nephronophthisis 4 (NPHP4) is associated with recessive cone-rod dystrophy in standard wire-haired dachshund. Genome Res (2008) 18(9):1415-21. doi:10.1101/gr.074302.107

5. Drogemuller C, Karlsson EK, Hytonen MK, Perloski M, Dolf G, Sainio K, et al. A mutation in hairless dogs implicates FOXI3 in ectodermal development. Science (2008) 321(5895):1462. doi:10.1126/science.1162525
Gate, Loop, or other professional networks, this allows you to post your articles or use your data without obtaining permission from a publisher.

- A collaborative interactive open review process: this can eliminate the frustrations, misconceptions, and seemingly endless revisions that inevitably accompany one-dimensional reviews. With Frontiers, authors discuss their rationale, clarify points, and address reviewers' concerns through an online interactive forum with reviewers and the associate editor. Reviewers work with authors to help improve manuscript quality. Should your manuscript be accepted, the names of reviewers and associate editor are published. This encourages constructive, informative critical review.

- Assessment of impact: Frontiers has a tiered impact system, which takes advantage of the best of social networking and media. Impact is not only based on citations but also number of downloads, page views, etc. A question that remains to be answered is: Does this method works better than that already in use?

Our goals with Veterinary Experimental and Diagnostic Pathology are to publish high-quality research that showcases the breadth and strength of veterinary pathology and to advance our discipline. In doing so, we maintain our relevance and inspire our successors. Can we accomplish our goal? Only if you, the investigators, readers, and reviewers support this vision, ask the questions, and conduct the studies, then publish your results after collaborative, respectful, and thoughtful review. Why don't you join us? I invite you to submit.

\section{AUTHOR CONTRIBUTIONS}

The author confirms being the sole contributor of this work and approved it for publication.

\section{ACKNOWLEDGMENTS}

The author thanks Dr. John Parker and Dr. Erica Behling-Kelly for critical review of the manuscript.

6. Willet CE, Makara M, Reppas G, Tsoukalas G, Malik R, Haase B, et al. Canine disorder mirrors human disease: exonic deletion in HES7 causes autosomal recessive spondylocostal dysostosis in miniature Schnauzer dogs. PLoS One (2015) 10(2):e0117055. doi:10.1371/journal.pone.0117055

7. Tryon RC, White SD, Bannasch DL. Homozygosity mapping approach identifies a missense mutation in equine cyclophilin B (PPIB) associated with HERDA in the American Quarter Horse. Genomics (2007) 90(1):93-102. doi:10.1016/j.ygeno.2007.03.009

8. Ayala-Valdovinos MA, Galindo-Garcia J, Sanchez-Chipres D, DuifhuisRivera T. New test for endothelin receptor type B (EDNRB) mutation genotyping in horses. Mol Cell Probes (2016) 30(3):182-4. doi:10.1016/j.mcp.2016. 03.005

9. Hayward JJ, Castelhano MG, Oliveira KC, Corey E, Balkman C, Baxter TL, et al. Complex disease and phenotype mapping in the domestic dog. Nat Commun (2016) 7:10460. doi:10.1038/ncomms 10460

10. Bronzini I, Aresu L, Paganin M, Marchioretto L, Comazzi S, Cian F, et al. DNA methylation and targeted sequencing of methyltransferases family genes in canine acute myeloid leukaemia, modelling human myeloid leukaemia. Vet Comp Oncol (2016). doi:10.1111/vco.12231 
11. Tallmadge RL, Shen L, Tseng CT, Miller SC, Barry J, Felippe MJ. Bone marrow transcriptome and epigenome profiles of equine common variable immunodeficiency patients unveil block of B lymphocyte differentiation. Clin Immunol (2015) 160(2):261-76. doi:10.1016/j.clim.2015.05.005

12. Galletti G, Sung MS, Vahdat LT, Shah MA, Santana SM, Altavilla G, et al. Isolation of breast cancer and gastric cancer circulating tumor cells by use of an anti HER2-based microfluidic device. Lab Chip (2014) 14(1):147-56. doi:10.1039/c3lc51039e

13. Liu J, Zhao J, Petrochenko P, Zheng J, Hewlett I. Sensitive detection of influenza viruses with Europium nanoparticles on an epoxy silica sol-gel functionalized polycarbonate-polydimethylsiloxane hybrid microchip. Biosens Bioelectron (2016) 86:150-5. doi:10.1016/j.bios.2016.06.044

14. Toubanaki DK, Athanasiou E, Karagouni E. Gold nanoparticle-based lateral flow biosensor for rapid visual detection of Leishmania-specific DNA amplification products. J Microbiol Methods (2016) 127:51-8. doi:10.1016/j. mimet.2016.05.027

15. Boushra M, Tous S, Fetih G, Korzekwa K, Lebo DB, Xue HY, et al. Development and evaluation of viscosity-enhanced nanocarrier (VEN) for oral insulin delivery. Int J Pharm (2016) 511(1):462-72. doi:10.1016/j.ijpharm.2016.07.016

16. Knorr F, Patzelt A, Darvin ME, Lehr CM, Schafer U, Gruber AD, et al. Penetration of topically applied nanocarriers into the hair follicles of dog and rat dorsal skin and porcine ear skin. Vet Dermatol (2016) 27(4):256-e60. doi:10.1111/vde.12325

17. Cabon Q, Sayag D, Texier I, Navarro F, Boisgard R, Virieux-Watrelot D, et al. Evaluation of intraoperative fluorescence imaging-guided surgery in cancer-bearing dogs: a prospective proof-of-concept phase II study in 9 cases. Transl Res (2016) 170:73-88. doi:10.1016/j.trsl.2015.12.001

18. Yao W, Xu P, Zhao J, Ling L, Li X, Zhang B, et al. RGD functionalized polymeric nanoparticles targeting periodontitis epithelial cells for the enhanced treatment of periodontitis in dogs. J Colloid Interface Sci (2015) 458:14-21. doi:10.1016/j.jcis.2015.07.032

19. Jenner D, Ducker C, Clark G, Prior J, Rowland CA. Using multispectral imaging flow cytometry to assess an in vitro intracellular Burkholderia thailandensis infection model. Cytometry A (2016) 89(4):328-37. doi:10.1002/cyto.a.22809

20. Ogle LF, Orr JG, Willoughby CE, Hutton C, McPherson S, Plummer R, et al. Imagestream detection and characterisation of circulating tumour cells - a liquid biopsy for hepatocellular carcinoma? J Hepatol (2016) 65(2):305-13. doi:10.1016/j.jhep.2016.04.014

21. Ploppa A, George TC, Unertl KE, Nohe B, Durieux ME. ImageStream cytometry extends the analysis of phagocytosis and oxidative burst. Scand J Clin Lab Invest (2011) 71(5):362-9. doi:10.3109/00365513.2011.572182

22. Taverna D, Norris JL, Caprioli RM. Histology-directed microwave assisted enzymatic protein digestion for MALDI MS analysis of mammalian tissue. Anal Chem (2015) 87(1):670-6. doi:10.1021/ac503479a

23. Camus MS, Flatland B, Freeman KP, Cruz Cardona JA. ASVCP quality assurance guidelines: external quality assessment and comparative testing for reference and in-clinic laboratories. Vet Clin Pathol (2015) 44(4):477-92. doi:10.1111/vcp.12299

24. Friedrichs KR, Harr KE, Freeman KP, Szladovits B, Walton RM, Barnhart KF, et al. ASVCP reference interval guidelines: determination of de novo reference intervals in veterinary species and other related topics. Vet Clin Pathol (2012) 41(4):441-53. doi:10.1111/vcp.12006
25. Webster JD, Dennis MM, Dervisis N, Heller J, Bacon NJ, Bergman PJ, et al. Recommended guidelines for the conduct and evaluation of prognostic studies in veterinary oncology. Vet Pathol (2011) 48(1):7-18. doi:10.1177/ 0300985810377187

26. Comazzi S, Avery PR, Garden OA, Riondato F, Rutgen B, Vernau W, et al. European canine lymphoma network consensus recommendations for reporting flow cytometry in canine hematopoietic neoplasms. Cytometry $B$ Clin Cytom (2016). doi:10.1002/cyto.b.21382

27. Priest HL, Hume KR, Killick D, Kozicki A, Rizzo VL, Seelig D, et al. The use, publication and future directions of immunocytochemistry in veterinary medicine: a consensus of the Oncology-Pathology Working Group. Vet Comp Oncol (2016). doi:10.1111/vco.12228

28. Hanel RM, Chan DL, Conner B, Gauthier V, Holowaychuk M, Istvan S, et al. Systematic evaluation of evidence on veterinary viscoelastic testing part 4: definitions and data reporting. J Vet Emerg Crit Care (2014) 24(1):47-56. doi:10.1111/vec.12145

29. Camus MS, Priest HL, Koehler JW, Driskell EA, Rakich PM, Ilha MR, et al. Cytologic criteria for mast cell tumor grading in dogs with evaluation of clinical outcome. Vet Pathol (2016). doi:10.1177/0300985816638721

30. Kiupel M, Webster JD, Bailey KL, Best S, DeLay J, Detrisac CJ, et al. Proposal of a 2-tier histologic grading system for canine cutaneous mast cell tumors to more accurately predict biological behavior. Vet Pathol (2011) 48(1):147-55. doi:10.1177/0300985810386469

31. Goldschmidt M, Pena L, Rasotto R, Zappulli V. Classification and grading of canine mammary tumors. Vet Pathol (2011) 48(1):117-31. doi:10.1177/ 0300985810393258

32. Anderson KB, Thomas SJ, Endy TP. The emergence of Zika virus: a narrative review. Ann Intern Med (2016) 165(3):175-83. doi:10.7326/M16-0617

33. Spengler JR, Stonecipher S, McManus C, Hughes-Garza H, Dow M, Zoran DL, et al. Management of a pet dog after exposure to a human patient with Ebola virus disease. J Am Vet Med Assoc (2015) 247(5):531-8. doi:10.2460/ javma.247.5.531

34. Feng N, Yu Y, Wang T, Wilker P, Wang J, Li Y, et al. Fatal canine distemper virus infection of giant pandas in China. Sci Rep (2016) 6:27518. doi:10.1038/ srep27518

35. Bamberger M, Oswald RE. Long-term impacts of unconventional drilling operations on human and animal health. JEnviron Sci Health A Tox Hazard Subst Environ Eng (2015) 50(5):447-59. doi:10.1080/10934529.2015.992655

36. Raffel TR, Halstead NT, McMahon TA, Davis AK, Rohr JR. Temperature variability and moisture synergistically interact to exacerbate an epizootic disease. Proc Biol Sci (2015) 282(1801):20142039. doi:10.1098/rspb.2014.2039

Conflict of Interest Statement: The author declares that the research was conducted in the absence of any commercial or financial relationships that could be construed as a potential conflict of interest.

Copyright () 2016 Stokol. This is an open-access article distributed under the terms of the Creative Commons Attribution License (CC BY). The use, distribution or reproduction in other forums is permitted, provided the original author(s) or licensor are credited and that the original publication in this journal is cited, in accordance with accepted academic practice. No use, distribution or reproduction is permitted which does not comply with these terms. 